\title{
Urgences
}

\section{URGENCES a deux ans !}

\section{Gilbert Dupuis}

Numéro 7, 2e trimestre 1983

URI : https://id.erudit.org/iderudit/025099ar

DOI : https://doi.org/10.7202/025099ar

Aller au sommaire du numéro

Éditeur(s)

Urgences

ISSN

0226-9554 (imprimé)

1927-3924 (numérique)

Découvrir la revue

Citer ce document

Dupuis, G. (1983). URGENCES a deux ans ! Urgences, (7), 5-6.

https://doi.org/10.7202/025099ar

Ce document est protégé par la loi sur le droit d'auteur. L'utilisation des services d'Érudit (y compris la reproduction) est assujettie à sa politique d'utilisation que vous pouvez consulter en ligne.

https://apropos.erudit.org/fr/usagers/politique-dutilisation/
Cet article est diffusé et préservé par Érudit.

Érudit est un consortium interuniversitaire sans but lucratif composé de l’Université de Montréal, l'Université Laval et l'Université du Québec à Montréal. Il a pour mission la promotion et la valorisation de la recherche. https://www.erudit.org/fr/ 


\section{URGENCES A DEUX ANS!}

Près de six cent pages de textes livrés par une cinquantaine d'auteurs différents constituent le bilan chiffré des sept premiers numéros de la revue URGENCES!

Depuis avril 1981, les contes, les nouvelles et les poèmes surtout tissent un grand texte, un réseau de correspondances. Alimentée principalement par les écrivains québécois qui animent la vie littéraire de l'Est du Québec, la revue rend compte de leurs intuitions, de leurs cris, de leurs appréhensions, de leur vie fragmentée. Depuis déjà deux ans... seulement!

Nous concevons la revue littéraire comme un lieu de rencontres, un carrefour des paroles, un laboratoire des tons et couleurs, nous entendons la revue comme une sorte de perron "passant", ouvert aux conteurs d'ici et d'ailleurs. Le comité de lecture gère les exigences de l'hospitalité en ouvrant le micro, guidé par une bienveillance responsable et une rigueur généreuse. Chaque numéro d'URGENCES se veut une soirée de racontages "pour voir", de confidences chuchotées et de grands rires équivoques.

Nous croyons à la communication littéraire comme mode d'expression libérant pour les femmes et les hommes de paroles et nous souhaitons que la revue véhicule les passagers les plus pressés de dire leur intensité, leur vie d'atelier, leurs impatiences, leurs urgences. II faudra bien d'autres soirées, d'autres voyages pour saisir la couleur et le ton singuliers de ce carrousel parlant à partir d'une région, d'un pays, d'un continent, d'une civilisation...

Le rayonnement des dires et des femmes/hommes qui les disent nous apparaît vital pour elles et eux, nous semble nécessaire pour leur voisinage infini. Puisse la revue continuer de s'avérer un haut-parleur 
pour les grands faiseurs de l'imaginaire, les placotteux du désespoir, les reporters de l'âme, pour les peintres du paysage intérieur, les amoureux de la "belle ouvra$\mathrm{ge}^{\prime \prime}$, pour les animateurs de l'espérance...

Nous appelons toute manifestation d'appui à la persistance de cet outil de développement culturel que constitue URGENCES; nous accueillerions tout télégramme dithyrambique, tout détournement d'héritage, tout simple abonnement avec reconnaissance et bonheur.

Place maintenant à neuf paroliers qui vous transmettront, nous l'espérons, le sentiment de la réelle urgence d'URGENCES.

Gilbert Dupuis pour le Comité de direction 